\title{
EXPRESSION OF BCL-2 IN BREAST CANCER: CORRELATION WITH CLINICOPATHOLOGICAL CHARACTERISTICS AND SURVIVAL
}

\author{
Filip Čečka ${ }^{1}$, Helena Hornychová ${ }^{2}$, Bohuslav Melichar ${ }^{3}$, Aleš Ryška ${ }^{2}$, Pavel Jandik ${ }^{1}$, Jindřiška Mergancová ${ }^{1}$, \\ Hana Klozová-Urminskáa
}

Charles University in Prague, Faculty of Medicine and University Hospital Hradec Králové, Czech Republic: Department of Surgery ${ }^{1}$; The Fingerland Department of Pathology ${ }^{2}$; Department of Oncology and Radiotherapy ${ }^{3}$; Department of Radiology ${ }^{4}$

Summary: Breast cancer is the most common malignancy in women. It is an immensely heterogeneous disease, characterised by a broad variety of clinical development. The research in recent years has focused on finding new markers of prognosis. This study investigates the role of expression of the bcl-2 protein in breast cancer. We analysed bcl-2 expression in 57 women with primary breast carcinoma who were treated with neoadjuvant (primary) chemotherapy, followed by a surgical procedure. The bcl-2 expression was correlated with other clinicopathological characteristics of the tumour - histological grade, stage, expression of hormonal receptors, proliferation rate, and with the survival of the patients. No significant association of bcl-2 expression with either overall survival or disease free survival was found.

Key words: Breast cancer; bcl-2; Apoptosis; Prognostic factor; Neoadjuvant chemotherapy

\section{Introduction}

Breast cancer is the most common malignancy in women not only in the Czech Republic, but also in the entire western world, with increasing incidence. However, the mortality of this disease has not increased that much. It is both due to improvements in the therapy as well as due to mammography screening in recent years. Nevertheless, apparently identical tumours may behave in a different way. This is the result of the fact that breast cancer is an immensely heterogeneous malignancy characterized by a broad variability of clinical development. Therefore, it is important to identify subgroups of patients bearing higher risk of relapse of the disease.

In breast cancer, the following prognostic factors are well accepted and widely used in routine practise:

1. Tumour size - one of the most powerful predictors of tumour behaviour in breast cancer $(9,17,54)$. Precise assessment of the tumour size is needed for adequate treatment.

2. Axillary lymph node status has been proved to be the most important predictor of disease-free survival and overall survival in breast cancer in numerous studies $(16,49,55)$. Between 20 to $30 \%$ of node negative breast cancer patients will develop a recurrence of the disease within 10 years, compared to about $70 \%$ of patients with positive axillary lymph nodes. The absolute number of positive lymph nodes is also of prognostic importance.

3. The histological grade is an important determinant of prognosis, and allows risk stratification within a tumour stage $(22,34)$.

4. Estrogen receptor and progesterone receptor determinations should be routinely performed in the diagnostic process of all breast cancer patients. Negative hormone receptor status is associated with worse prognosis for the patient $(3,5,40)$. However, its main importance is in predicting the response to hormonal therapy.

5. Her-2/neu gene amplification results in overexpression of the encoded transmembrane oncoprotein, belonging to the family of tyrosine kinase growth factor receptors. The amplification of the gene/overexpression of the protein is present in about one third of all breast cancers (48). Her-2/neu positivity is associated with higher histological grade and reduced survival (2). The recently developed humanized monoclonal antibody trastuzumab (Herceptin) is used for the treatment of patients with Her-2/neu positive tumours. High expression of Her-2/neu oncoprotein can predict the success of molecular targeted therapy with trastuzumab (21). Thus, Her$2 /$ neu analysis is necessary to obtain both prognostic and predictive data.

Approximately one third of breast cancers have mutations of the tumour suppressor gene p53, which is asso- 
ciated with a higher histological grade and higher clinical aggressiveness of the disease (4). The already mentioned p53 appears to be a useful prognostic marker, particularly in node-negative breast cancer patients (1).

Expression of $\mathrm{Ki}-67$ protein is used as a marker of cell proliferation and can have a prognostic role in breast cancers (37). Ki-67 is a labile nuclear protein that cannot be detected in resting (G0) cells, but is expressed in the G1 through $\mathrm{M}$ phases of the cell cycle.

Other factors which can be detected in breast cancer tissue samples, and are not used in routine practise yet, include: epidermal growth factor receptor (EGFR) (52), cyclins A, B, D, and E $(27,28,32,53)$, survivin, one of the inhibitor of the apoptosis protein family (26), vascular endothelial growth factor (VEGF) (13) and Cathepsin D (19, 24). Among numerous prognostic factors, bcl-2 was also considered as one of possible promising markers.

Bcl-2 (acronym for the B-cell lymphoma/leukemia-2 gene) was first discovered in B-cell malignancies (51). Specific translocation moves bcl-2 gene from its normal location at $18 \mathrm{q} 21$ into the locus at $14 \mathrm{q} 32$, resulting in permanent activation of bcl-2 gene and overproduction of bcl-2 protein (42).

The family of bcl-2 proteins are mitochondrial proteins regulating apoptosis. By forming a complex network of homo- and heterodimers, they either inhibit or advance apoptosis. Relative ratios of antiapoptotic proteins (bcl-2, mcl-1, bcl-X) and proapoptotic proteins (bax) then determine the behaviour of the cell and the response to various apoptotic stimuli, such as cytostatic agents $(20,43)$. Clinical studies have shown that from this family of proteins, bcl-2 itself has the greatest value as a prognostic factor $(31,14,33)$.

In preclinical studies, bcl-2 protein inhibits apoptosis in vitro and is associated with chemoresistance $(15,50,56)$. For this reason it has been hypothesized that bcl-2 protein overexpression may play a role in the resistance to chemotherapy. In vivo, the expression of bcl-2 protein should inhibit apoptosis and therefore should mean a worse outcome for the patients. Surprisingly, statistical analysis revealed that bcl-2 positive patients had better prognosis and better survival, compared with patients with bcl-2 negative tumours $(46,57)$.

Several possible explanations for these seemingly paradoxical results have been suggested (30):

1) bcl-2 not only inhibits apoptosis, but also has an inhibitory effect on cell proliferation (41);

2) bcl-2 expression is regulated by estrogens (23);

3) bcl-2 antagonists are present in tumour cells, negating cytoprotective function of bcl-2 (29).

The purpose of our study was to elucidate the prognostic role of bcl-2 in breast cancer. We analysed the bcl-2 expression in breast cancer tissue using immunohistochemistry and studied its relationship to well accepted prognostic markers. Also, we investigated the association between the expression of bcl-2 and survival of the patients. Based on the knowledge from previous studies, we hypothesized that negative or weak bcl-2 expression could indicate a more aggressive phenotype of breast cancer and might therefore mean worse prognosis for the patient.

\section{Material and Methods}

\section{Patients}

The study comprised 57 women with primary breast carcinoma who were treated with neoadjuvant (primary) chemotherapy in the University Hospital in Hradec Králové, Czech Republic between 1999 and 2003. To be included in the study, the patients had to meet the following criteria: no history of previous malignancy and no evidence of metastatic disease at the time of diagnosis.

At the time of diagnosis, histological verification of breast carcinoma was obtained from core-cut biopsy tissue samples.

The treatment was commenced with neoadjuvant chemotherapy, in a combination of doxorubicin $\left(50 \mathrm{mg} / \mathrm{m}^{2}\right)$ and paclitaxel $\left(175 \mathrm{mg} / \mathrm{m}^{2}\right), 6$ cycles in 3 week regimens.

Response to the neoadjuvant chemotherapy was evaluated in a standard manner. Clinical complete response was defined as no sign of the tumour on mammography prior to surgery. Pathological complete response was defined as no residual tumour in the surgical specimen. Partial response, stable disease and progressive disease were then evaluated according to the results of the mammography examination. Partial response was defined as more than $50 \%$ reduction of the tumour. Stable disease was defined as between $50 \%$ reduction and $25 \%$ increase in tumour size. Progressive disease was defined as more than $25 \%$ increase in tumour size.

Neoadjuvant chemotherapy was followed by a surgical procedure, which was either modified radical mastectomy (ablation of breast gland with pectoral fascia and axillary lymph node dissection, including level I and II) or partial mastectomy (removing part of mammary gland with tumour), with axillary lymph node dissection. All patients who were treated with partial mastectomy were given postoperative radiotherapy to the breast. The patients were then followed in the Department of Oncology and Radiotherapy, University Hospital in Hradec Králové every 3 months. Bilateral mammography, chest X-ray, skeletal scintigraphy and hepatic ultrasonography were carried out once a year. Patients with signs of metastatic disease underwent further investigations. Disease-free survival was calculated as the time from the date of diagnosis to documented relapse and overall survival was calculated as the time from the date of diagnosis to death.

\section{Histological and immunohistochemical examination}

All specimens were fixed in $10 \%$ formalin and embedded in paraffin. For each specimen, 4- $\mu$ m sections were cut and stained with hematoxylin and eosin. Histological type and grade was examined in the core-cut biopsy, as well as in 
the surgical specimen. In the core-cut biopsy, immunohistochemical analysis was performed using the streptavidin-biotin method with peroxidase detection system (En Vision, DAKO). The monoclonal primary antibodies against the following antigens were used: estrogen receptor (1D5, DAKO), progesterone receptor (PgR636, DAKO), Ki-67 (MIB-1, DAKO), p53 (DO-7, DAKO), bcl-2 (124, DAKO). A HercepTest $^{\mathrm{TM}}$ Kit (DAKO) was used to detect the overexpression of Her-2/neu. Appropriate tissue specimens were used as positive controls. Examined markers were evaluated in a standard manner: IRS (immunoreactive score) for ER and PgR (range 0-12) (44); for Ki-67 the percentage of positive cells was determined semiquantitatively; Her score was used for the evaluation of Her-2/neu (0-3), according to manufacturer's instructions. Immunostaining for $\mathrm{p} 53$ and bcl-2 was evaluated using a semiquantitative system. Expression was scored 0 to 3 based on the intensity of staining: 0 none, 1 weak, 2 intermediate, 3 strong signal; and the percentage of positive cells was counted: 0 none, 1 (1\%), $2(2-10 \%), 3(11-30 \%), 4$ (31-60\%), 5 (more than $60 \%)$. The overall score was then expressed as the summation of the proportion and intensity scores (11). One pathologist evaluated all slides for bcl-2 immunostaining in a blind fashion, without knowledge of other clinicopathological data.

\section{Statistical Methods}

Association between the bcl-2 expression and $\mathrm{Ki}-67$, and tumour size was analysed by the Kruskal-Wallis non-parametric Analysis of Variance (ANOVA). Associations between the bcl-2 expression and other variables were evaluated by the chi-square test of independence in contingency tables or the Fisher's exact test. Significance was defined at the $\mathrm{p}<0.05$ level. The disease-free survival and overall survival curves were estimated by the Kaplan-Meier survival curves. The logrank test was used to assess the differences between the curves.

\section{Results}

Patients' characteristics are shown in Table 1. Fifty-seven patients were included in the study. Radical modified mastectomy with axillary lymph node dissection was performed in 25 cases ( $44 \%$ ). Partial mastectomy with axillary lymph node dissection was performed in 32 cases (56\%).

Clinical complete response to the neoadjuvant chemotherapy was achieved in 9 cases $(15.8 \%), 7$ out of which $(12.3 \%)$ had also pathological complete response. Partial response was achieved in 27 cases $(47.3 \%)$. Stable disease was seen in 20 patients $(35.1 \%)$ and progressive disease occurred in one patient ( $1.8 \%)$.

A semiquantitative system was used for evaluation of bcl-2 protein expression. The frequency of bcl-2 scores (0-8) are shown in Figure 1.

Table 2 summarizes the association between the bcl-2 expression and other variables. Bcl-2 expression was signi-
Tab. 1: Patients' characteristics.

\begin{tabular}{|c|c|c|}
\hline Age & $\begin{array}{c}\text { Median } \\
\text { Range }\end{array}$ & $\begin{array}{c}56 \\
38-74\end{array}$ \\
\hline \multirow{7}{*}{$\begin{array}{c}\text { TNM } \\
\text { classification }\end{array}$} & $\mathrm{T} 1$ & $2(3.5 \%)$ \\
\hline & $\mathrm{T} 2$ & $24(42.1 \%)$ \\
\hline & T3 & $12(21.1 \%)$ \\
\hline & $\mathrm{T} 4$ & $19(33.3 \%)$ \\
\hline & No & $14(24.6 \%)$ \\
\hline & N1 & $34(59.6 \%)$ \\
\hline & $\mathrm{N} 2$ & $9(15.8 \%)$ \\
\hline \multirow[t]{4}{*}{ Histology } & ductal carcinoma & $46(80.6 \%)$ \\
\hline & lobular carcinoma & $9(15.8 \%)$ \\
\hline & papilar carcinoma & $1(1.8 \%)$ \\
\hline & $\begin{array}{l}\text { dediferentiated } \\
\text { carcinoma }\end{array}$ & $1(1.8 \%)$ \\
\hline \multirow[t]{3}{*}{ Grade } & G I & $1(1.8 \%)$ \\
\hline & G II & $29(50.9 \%)$ \\
\hline & G III & $27(47.3 \%)$ \\
\hline \multirow[t]{2}{*}{ ER } & IRS score $0-4$ & $29(50.9 \%)$ \\
\hline & IRS score 5-12 & $28(49.1 \%)$ \\
\hline \multirow[t]{2}{*}{ PR } & IRS score $0-4$ & $38(66.7 \%)$ \\
\hline & IRS score $5-12$ & $19(33.3 \%)$ \\
\hline \multirow[t]{2}{*}{ p53 } & score $0-2$ & $34(59.6 \%)$ \\
\hline & score $3-8$ & $23(40.4 \%)$ \\
\hline \multirow[t]{3}{*}{ Ki-67 } & $0-10 \%$ & $9(15.8 \%)$ \\
\hline & $11-20 \%$ & $15(26.3 \%)$ \\
\hline & $21-100 \%$ & $33(57.9 \%)$ \\
\hline \multirow[t]{2}{*}{ Her score } & negative $(0-1)$ & $42(73.7 \%)$ \\
\hline & positive (2-3) & $15(26.3 \%)$ \\
\hline \multirow{2}{*}{$\begin{array}{l}\text { type of surgical } \\
\text { procedure }\end{array}$} & $\mathrm{ME}+\mathrm{EA}$ & $25(43.9 \%)$ \\
\hline & $\mathrm{pME}+\mathrm{EA}$ & $32(56.1 \%)$ \\
\hline
\end{tabular}

Tab. 2: Association between Bcl-2 expression and other variables.

\begin{tabular}{|c|c|}
\hline variables & $\mathbf{p}$ \\
\hline tumour size & 0.56 \\
\hline grading & 0.53 \\
\hline ER & 0.003 \\
\hline PR & 0.36 \\
\hline Ki-67 score & 0.07 \\
\hline Her-2/neu & 0.24 \\
\hline p53 & 0.88 \\
\hline
\end{tabular}

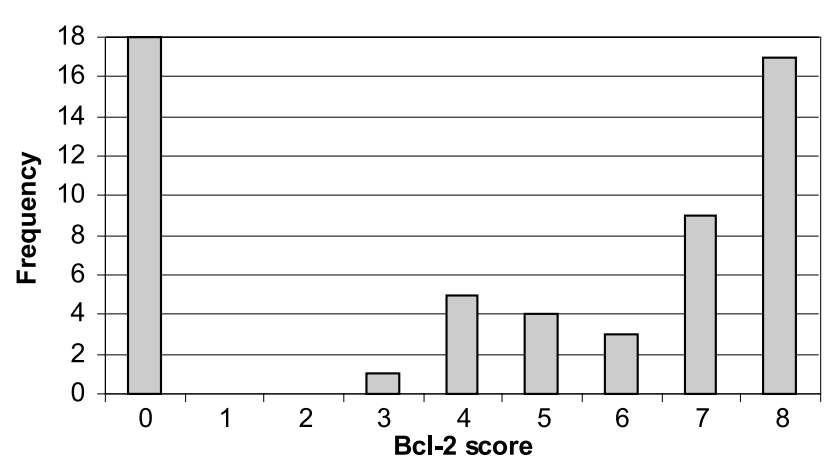

Fig. 1: The frequency or scores of Bcl-2 expression. 
ficantly related to estrogen receptor status only $(p=0,003)$. There was an association between the bcl-2 expression and the proliferation index Ki-67, but it was not statistically significant $(\mathrm{p}=0.07)$. We found no significant correlation between the expression of bcl-2 and other variables in our group of patients.

At the median follow-up period (58 months; range 25-96 months), the disease free survival (DFS) and overall survival (OS) were $70 \%$ and $77 \%$, respectively. Thirteen deaths for cancer-related causes had occurred and 17 recurrences, 3 of which were locoregional recurrences and 14 distant metastases.

Kaplan-Meier curves were used to estimate survival for bcl-2 negative and positive tumours. Observed bcl-2 negativity showed a trend toward association with a shorter

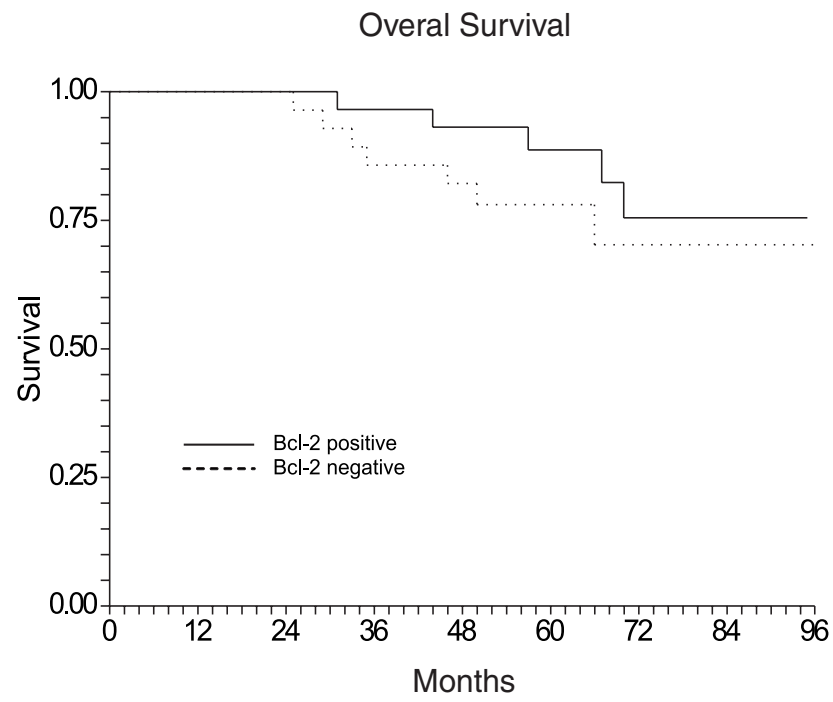

Fig. 2: Kaplan-Meier curve for overall survival.

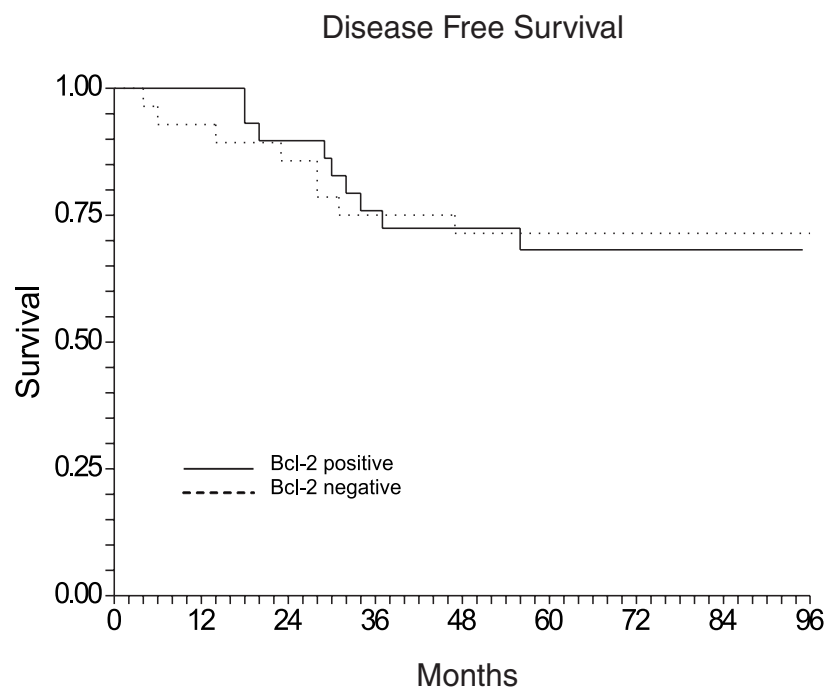

Fig. 3: Kaplan-Meier curve for disease free survival. overall survival, but it was not statistically significant (Fig. 2). Regarding disease free survival, we found no association with bcl-2 protein expression (Fig. 3). Nevertheless, due to the small number of patients included in this statistical analysis, these findings should be interpreted with caution.

\section{Discussion}

Breast cancer is a disease with variable clinical development and prognosis. The presence of alterations in molecular mechanisms affects tumour growth, proliferation, progression and metastatic potential. This limits significantly the prognostic value of the TNM staging system. Therefore, various biomarkers are used as a complement to clinicopathological staging in order to identify patients at a higher risk of relapse (who need more aggressive systemic treatment). In our study, we tried to find an association between expression of bcl-2 protein and survival of the patients. We examined bcl-2 expression using a semiquantitative method in patients treated with neoadjuvant chemotherapy followed by a surgical procedure.

Our hypothesis was that negative or weak bcl-2 expression would mean a worse prognosis for the patients. However, the results of this study suggest that bcl-2 expression does not have such a prognostic significance. In this regard, our results are in contrast with studies that suggest that bcl-2 expression is a favourable prognostic factor when primary surgical therapy is used. In other studies bcl-2 expression has been found to be an independent predictor of prognosis $(7,8,12,10,18,38)$. However, other studies have shown opposite results $(6,25,35,36,47)$. In concordance with our study, bcl-2 expression was not proved to be a favourable prognostic marker in studies where patients were treated with neoadjuvant chemotherapy $(11,39)$.

In one of the largest studies evaluating the prognostic significance of bcl-2 (45), Rolland et al. deteced bcl-2 protein expression in tissue from 819 patients with primary resected breast cancer. Their results showed that bcl-2 alone did not have an independent prognostic significance. However, the p53(+) bcl-2(-) phenotype remained independently associated with a worse prognosis. Such discrepancies between the studies are likely to be due to the wide variation between the methodologies, types of cases, and various treatments schemes studied.

\section{Conclusion}

Bcl-2 appears to play an important part in regulation of apoptosis and proliferation in breast cancer cells.

However, the behaviour of this pathway is very complex. It seems necessary to study more biomarkers, not only bcl-2, on a larger number series of patients to assess the prognosis of patients treated with neoadjuvant chemotherapy. 


\section{Acknowledgements \\ The authors thank RNDr. Eva Čermáková for the help with statistical analysis of the results. The work was sup- ported by grant from the Medical Faculty in Hradec Králové, Charles University in Prague, Grant No. 84121.}

\section{References}

1. Allred DC, Clark GM, Elledge R, et al. Accumulation of mutant p53 is associated with increased proliferation and poor clinical outcome in node negative breast cancer. J Natl Cancer Inst 1993:85:200-6.

2. Allred DC, Clark GM, Molina R, et al. Overexpression of HER-2/neu and its relationship with other prognostic factors change during the progression of in situ to invasive breast cancer. Hum Pathol 1992;23:974-9.

3. Allred DC, Harvey JM, Berardo M, Clark GM. Prognostic and predictive factors in breast cancer by immunohistochemical analysis. Mod Pathol 1998;11: 155-68.

4. Barnes DM, Dublin EA, Fisher CJ, Levison DA, Millis RR. Immunohistochemical detection of $\mathrm{p} 53$ protein in mammary carcinoma: an important new independent indicator of prognosis? Hum Pathol 1993;24:469-76.

5. Barnes DM, Harris WH, Smith P, Millis RR, Rubens RD. Immunohistochemical determination of oestrogen receptor: comparison of different methods of assessment of staining and correlation with clinical outcome of breast cancer patients. Br J Cancer 1996;74:1445-51.

6. Beenken SW, Grizzle WE, Crowe DR, et al. Molecular biomarkers for breast cancer prognosis: coexpression of c-erbB-2 and p53. Ann Surg 2001;233:630-8.

7. Bhatavdekar JM, Patel DD, Shah NG, et al. Prognostic significance of immunohistochemically localized biomarkers in stage II and stage III breast cancer: a multivariate analysis. Ann Surg Oncol 2000;7:305-11.

8. Callagy GM, Pharoah PD, Pinder SE, et al. Bcl-2 is a prognostic marker in breas cancer independently of the Nottingham Prognostic Index. Clin Cancer Res 2006;12:2468-75.

9. Carter CL, Allen C, Henson DE. Relation of tumor size, lymph node status, and survival in 24,740 breast cancer cases. Cancer 1989;63:181-7.

10. Castiglione F, Sarotto I, Fontana V, et al. Bcl2, p53 and clinical outcome in a series of 138 operable breast cancer patients. Anticancer Res 1999;19:4555-63.

11. Chang J, Powles TJ, Allred DC, et al. Biologic markers as predictors of clinica outcome from systemic therapy for primary operable breast cancer. J Clin Oncol 1999; 17:3058-63.

12. Charpin C, Garcia S, Bonnier P, et al. bcl-2 automated and quantitative immunocytochemical assays in breast carcinomas: correlation with 10-year follow-up. J Clin Oncol 1998;16:2025-31.

13. Coradini D, Biganzoli E, Pellizzaro C, et al. Vascular endothelial growth factor in node-positive breast cancer patients treated with adjuvant tamoxifen. $\mathrm{Br} \mathrm{J}$ Cancer 2003;89:268-70

14. Daidone MG, Luisi A, Martelli G, et al. Biomarkers and outcome after tamoxifen treatment in node-positive breast cancers from elderly women. Br J Cancer 2000;82:270-7.

15. Del Bufalo D, Biroccio A, Leonetti C, Zupi G. Bcl-2 overexpression enhances the metastatic potential of a human breast cancer line. FASEB J 1997;11:947-53.

16. Fisher ER, Anderson S, Redmond C, Fisher B. Pathologic findings from the National Surgical Adjuvant Breast Project Protocol B-06: 10-year pathologic and clinical prognostic discriminants. Cancer 1993;71:2507-14.

17. Fisher ER, Sass R, Fisher B. Pathologic findings from the National Surgica Adjuvant Breast Project for breast cancers (protocol no 4): discrimination for tenth year treatment failure. Cancer 1984;53(suppl. 3):712-23.

18. Gasparini G, Barbareschi M, Doglioni C, et al. Expression of bcl-2 protein predicts efficacy of adjuvant treatments in operable node-positive breast cancer. Clin Cancer Res 1995;1:189-98.

19. Gion M, Mione R, Dittadi R, et al. Relationship between cathepsin D and other pathologic and biological parameters in 1752 patients with primary breast cancer. Eur J Cancer 1995;31:671-7.

20. Gross A, McDonnell JM, Korsmeyer SJ. BCL-2 family members and the mitochondria in apoptosis. Genes Dev 1999;13:1899-911.

21. Harries M, Smith I. The development and clinical use of trastuzumab (Herceptin). Endocr Relat Cancer 2002;9:72-85.

22. Henson DE, Ries L, Freedman LS, Carriaga M. Relationship among outcome, stage of disease, and histologic grade for 22,616 cases of breast cancer. The basis for a prognostic index. Cancer 1991;68:2142-9.

23. Huang Y, Ray S, Reed JC, et al. Estrogen increases intracellular p26Bcl-2 to p21Bax ratios and inhibits taxol-induced apoptosis of human breast cancer MCF7 cells. Breast Cancer Res Treat 1997;42:73-81.
24. Isola J, Weitz S, Visakorpi T, et al. Cathepsin D expression detected by immunohistochemistry has independent prognostic value in axillary node negative breast cancer. J Clin Oncol 1993;11:36-43.

25. Jansen RL, Joosten-Achjanie SR, Volovics A, et al. Relevance of the expression of bcl-2 in combination with p53 as a prognostic factor in breast cancer. Anticancer Res 1998;18:4455-62.

26. Kennedy SM, O’Driscoll L, Purcell R, et al. Prognostic importance of survivin in breast cancer. Br J Cancer 2003;88:1077-83.

27. Kenny FS, Hui R, Musgrowe EA, et al. Overexpression of cyclin D1 messenger RNA predicts for poor prognosis in estrogen receptor-positive breast cancer. Clin Cancer Res 1999;5:2069-76.

28. Keyomarsi K, Tucker SL, Buchholz TA, et al. Cyclin E and survival in patients with breast cancer. N Engl J Med 2002;347:1566-75.

29. Krajewski S, Blomvqvist C, Franssila K, et al. Reduced expression of pro-apoptotic gene Bax is associated with poor response rates to combination chemotherapy and shorter survival in women with metastatic breast adenocarcinoma. Cancer Res 1995;55:4471-8.

30. Krajewski S, Krajewska M, Turner BC, et al. Prognostic significance of apoptosis regulators in breast cancer. Endocr Relat Cancer 1999;6:29-40.

31. Krajewski S, Thor AD, Edgerton SM, Moore DH, Krajewska M, Reed JC. Analysis of Bax and Bcl-2 expression in p53-immunopositive breast cancers. Clin Cancer Res 1997;3:199-208.

32. Kuhling H, Alm P, Olsson H, et al. Expression of cyclins E, A, and B, and prognosis in lymph node-negative breast cancer. J Pathol 2003;199:424-31.

33. Kymionis GD, Dimitrakakis CE, Konstadoulakis MM, et al. Can expression of apoptosis genes, bcl-2 and bax, predict survival and responsiveness to chemotherapy in node-negative breast cancer patients? J Surg Res 2001;99:161-8.

34. Le Doussal V, Tubiana-Hulin M, Friedman S, et al. Prognostic value of histologic grade nuclear components of Scarff-Bloom-Richardson (SBR): an improved score modification based on multivariate analysis of 1262 invasive ductal breast carcinomas. Cancer 1989;64:1914-21.

35. Linjawi A, Kontogiannea M, Halwani F, Edwardes M, Meterissian S. Prognostic significance of $\mathrm{p} 53, \mathrm{bcl}-2$, and Bax expression in early breast cancer. J Am Coll Surg 2004;198:83-90.

36. Megha T, Ferrari F, Arcuri F, et al. Cellular kinetics and expression of bcl-2 and p53 in ductal carcinoma of the breast. Oncol Rep 2000;7:473-8.

37. Molino A, Micciolo R, Turazza M, et al. Ki-67 immunostaining in 322 primary breast cancers: association with clinical and pathological variables and prognosis. Int J Cancer 1997:74:433-7.

38. Neri A, Marrelli D, Roviello F, et al. Bcl-2 expression correlates with lymphovascular invasion and long-term prognosis in breast cancer. Breast Cancer Res Treat 2006;99:77-83

39. Pernick NL, Biernat L, Du W, Visscher DW. Clinicopathologic analysis of Fas, Fas ligand, and other biomarkers in locally advanced breast carcinoma. Breast J 2000;6:233-41.

40. Pertschuk LP, Kim DS, Nayer K, et al. Immunocytochemical estrogen and progestin receptor assays in breast cancer with monoclonal antibodies. Histopathologic, demographic, and biochemical correlations and relationship to endocrine response and survival. Cancer 1990;66:1663-70.

41. Reed JC. Balancing cell life and death: Bax, apoptosis, and breast cancer. J Clin Invest 1996;97:2403-4.

42. Reed JC. Bcl-2 and the regulation of programmed cell death. J Cell Biol 1994; 124:1-6.

43. Reed JC. Mechanisms of apoptosis. Am J Pathol 2000;157:1415-30.

44. Remmele W, Stegner HE. Recommendation for uniform definition of an immunoreactive score (IRS) for immunohistochemical estrogen receptor detection (ER-ICA) in breast cancer tissue. Pathologe 1987;8:138-40.

45. Rolland P, Spendlove I, Madjid Z, et al. The p53 positive Bcl-2 negative phenotype is an independent marker of prognosis in breast cancer. Int J Cancer 2007; 120:1311-7.

46. Silvestrini R, Benini E, Veneroni S, et al. p53 and bcl-2 expression correlates with clinical outcome in a series of node-positive breast cancer patients. J Clin Oncol 1996; 14:1604-10.

47. Silvestrini R, Veneroni S, Daidone MG, et al. The Bcl-2 protein: a prognostic indicator strongly related to $\mathrm{p} 53$ protein in lymph node-negative breast cancer patients. J Natl Cancer Inst 1994;86:499-504.

48. Slamon DJ, Clark GM, Wong SG, Levin WJ, Ullrich A, McGuire WL. Human breast cancer: correlation of relapse and survival with amplification of the HER2/neu oncogene. Science 1987;235:177-82.

49. Smith JA, Gamez-Araugo JJ, Gallager HS, et al. Carcinoma of the breast: analysis of total lymph node involvement versus level of metastasis. Cancer 1977;39: 527-32

50. Teixeira C, Reed JC, Pratt MA. Estrogen promotes chemotherapeutic drug resistance by a mechanism involving $\mathrm{Bcl}-2$ proto-oncogene expression in human breast cancer cell. Cancer Res 1995;55:3902-7. 
51. Tsujimoto Y, Croce CM. Analysis of the structure, transcripts, and protein products of bcl-2, the gene involved in human follicular lymphoma. Proc Natl Acad Sci USA 1986;83:5214-8.

52. Tsutsui S, Kataoka A, Ohno S, Murakami S, Kinoshita J, Hachitanda Y. Prognostic and predictive value of epidermal growth factor receptor in recurrent breast cancer. Clin Cancer Res 2002;8:3454-60.

53. Umekita Y, Ohi Y, Sagara Y, Yoshida H. Overexpression of cyclin D1 predicts for poor prognosis in estrogen receptor-negative breast cancer patients. Int J Cancer 2002;98:415-8.

54. Veronesi U, Cascinelli N, Greco M, et al. Prognosis of breast cancer patients after mastectomy and dissection of internal mammary nodes. Ann Surg 1985;202: 702-7.

55. Veronesi U, Galimberti V, Zurrida S, et al. Prognostic significance of number and level of axillary nodal metastases in breast cancer. Breast 1993;2:224-8.

56. Zapata JM, Krajewska M, Krajewski S, et al. Expression of multiple apoptosis-regulatory genes in human breast cancer cell lines and primary tumors. Breast Cancer Res Treat 1998;47:129-40.

57. Zhang GJ, Kimijima I, Abe R, et al. Apoptotic index correlated to Bcl-2 and p53 protein expression, histological grade and prognosis in invasive breast cancers. Anticancer Res 1998;18:1989-98.

Submitted March 2008.

Accepted April 2008.

\section{Corresponding author:}

Filip Čečka, M.D., University Hospital Hradec Králové, Department of Surgery,

Sokolská 581, 50005 Hradec Králové, Czech Republic, e-mail: filip.cecka@seznam.cz 